Proceedings of the Annual Scientific Meeting, 19th to 21st July 1973Part I.

\title{
THE ORTHOSIS FOR RESTORATION OF PREHENSILE FUNCTION IN TETRAPLEGICS
}

By Prof. G. ZRubecky, M.D. and M. StöGer, M.D.

Rehabilitation centre of the Allgemeinen Unfallsversicherungsanstalt

Tobelbad bei Graz, Austria

\section{INTRODUCTION}

IN the rehabilitation of paraplegics the individual circumstances and needs of each patient have to be taken into account. With tetraplegics the restoration of prehensile function is of utmost significance. The severity of functional loss depends

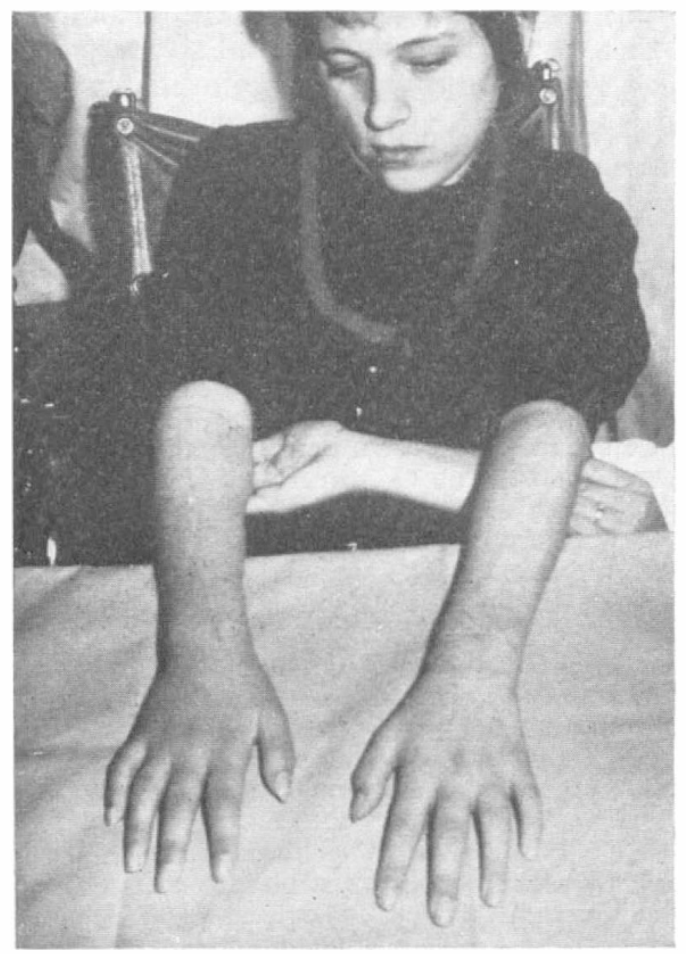

FIG. I

A female, aged I7, fracture of fourth cervical vertebra with complete loss of functions.

upon the level of injury, i.e. high cervicals are completely helpless. The main problem in rehabilitation is improving the remaining movements and coping with 
the absolute helplessness in daily life. Only if the rehabilitation is successful are the patients able to engage themselves in everyday activities such as reading,

Fig. 2.-A I6-year-old student. Fracture of the fif th cervical vertebra and complete loss of functions. With an injury at this level there is no active movement in the fingers and the wrist.

Fig. 3.-Left above the electrodes which are applied on the skin. The bioelectric currents are directed to an amplifier and thence to a motor which moves the orthosis via Bowden-cables.

Fig. 4.-A 25-year-old male with a complete $\mathrm{C}_{5}$ traumatic lesion. $\mathrm{He}$ is feeding himself with a myoelectric hand in the intermediate stage of the orthosis-training. To stabilise the sitting position in the wheelchair one hand is placed behind the back of the wheelchair, so that the upper part of the body is fixed.

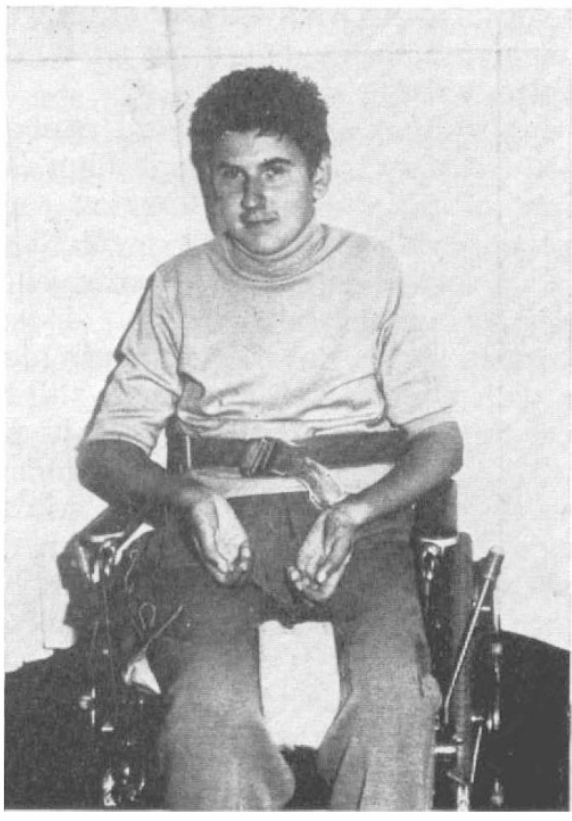

FIG. 2

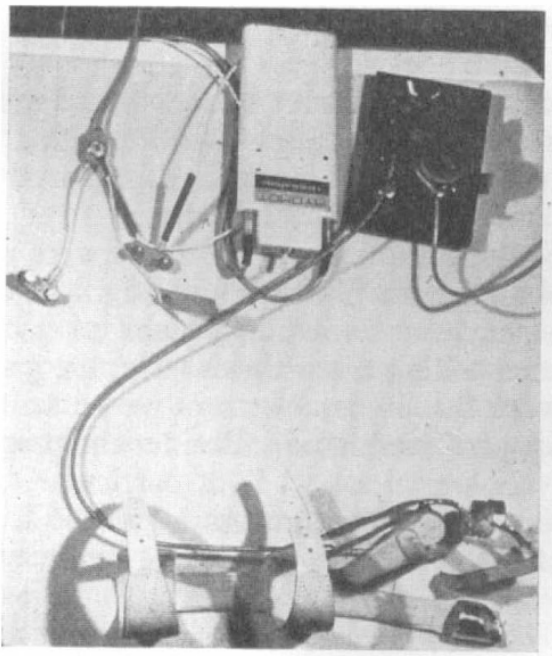

FIG. 3

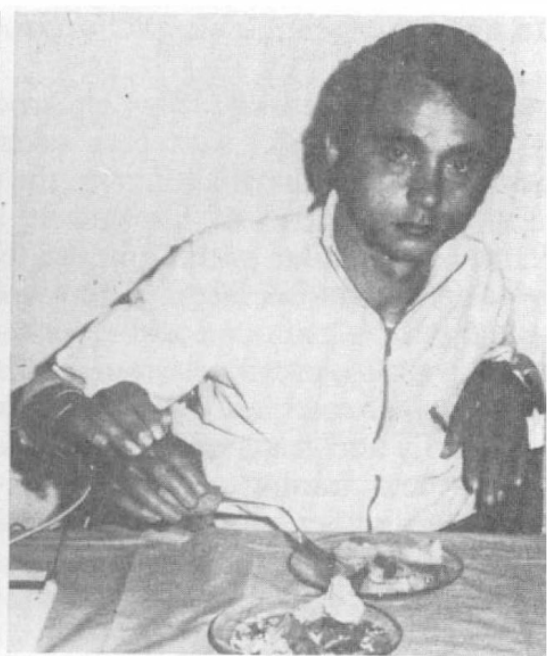

FIG. 4

telephoning, writing, etc. Therefore, it is clear that all possibilities must be made use of to enable disabled persons to perform at least primitive prehensile functions. For high tetraplegics 'grasping means life' in the true sense of the word. 
Indications for a Myoelectric Orthosis. After a fracture of the fourth cervical vertebra and complete loss of function the patients have only moderate shoulder and elbow flexion control (fig. I). Patients who sustained a cervical cord lesion below $\mathrm{C}_{5}$ with complete loss of functions, are able to move the hand, usually flaccid paralysed, to the mouth but are neither able to extend the elbow nor move the forearm, wrist or fingers (fig. 2).

Owing to functional-anatomical reasons a surgical reconstruction by muscle or tendon transfers is impossible in high complete cervical lesions. Therefore, a restoration of the prehensile function can only be performed successfully by technical aids with an externally powered orthosis. At the Rehabilitation centre Tobelbad the orthoses with myoelectric control is used for patients with a complete $\mathrm{C}_{4}$ or $\mathrm{C}_{5}$ traumatic lesion (fig. 3). This device makes the gradated tridigital pinch, formed by the tips of the thumb, index and middle fingers possible. Even patients with a high level injury may still have some protective sensibility at the tips of the fingers and the orthosis permits the patient to obtain a muscular gradated pinch with sensibility. Long (1970) from the Case Western Reserve University in Cleveland, reported that myoelectric hand splints were rejected by high tetraplegic ( $\mathrm{C}_{4}$ and $\left.\mathrm{C}_{5}\right)$ patients. When discharged from hospital none of the patients continued to use the myoelectric hand splint, the main reasons being slow speed of application and performance of activities and poor quality of performance of activities. Other authors (Stauffer \& Nickel, I973) state that if the control muscle is inadvertently contracted, the hand splint may either open or close by mistake. With a new system of myoelectric control new myoelectric orthoses were developed at the Institute of Technology in Graz, which are technically simpler and less susceptible to repairs than the former ones were.

This orthosis displays a hold firm enough for the patient to perform a second grip if necessary, so that whatever the patient holds is not dropped as soon as there are involuntary impulses (Schuy, I973).

Methods of Training. Skin electrodes are placed over an innervated muscle (usually brachioradialis). Currents taken from this muscle are amplified and transmitted to an engine which moves the orthosis. It is important for the patient to have a visual control of his muscle activity (Stöger \& Lederer, I971). A myoelectric hand similar to those in use for the common arm prothesis were used. This myoelectric hand is fastened to a volar forearm plastic splint (fig. 4). Now the disabled person can open and close the myoelectric hand through innervation of the muscle group, previously tested for controlling the orthosis. So, the patient with a high spinal cord lesion becomes aware that he is able to move an artificial hand voluntarily and gradated in spite of his paralysed hand. Besides the practical effect of this new training method the psychological aspect is of particular significance for the further progress of rehabilitation. After a training of 4-6 weeks, depending on age and intelligence, the final orthosis is made to.measure and manufactured (fig. 5, A-C).

Adaption of the Myoelectric Device to One Hand only. At the beginning of this programme it was proposed to adapt both hands with myoelectric orthosis. These experiments, however, failed. It was found that tetraplegics with a complete $\mathrm{C}_{4}, \mathrm{C}_{5}$ traumatic lesion always use just the one hand for all activities though they have an orthosis adapted to each hand. In spite of intensive training, the aim 
of one patient using both hands simultaneously and well-coordinated, e.g. for eating, was not achieved. Eventually the reason for this was found. The act of grasping begins at the shoulder and ends in the differentiated motions of the fingers, working like the arm of a caterpillar (fig. 6). The shoulder, however, can only be put to effective use as soon as the body is held in the proper position. Owing to paralysis of trunk muscles this physiological process of movement is discontinued, in other words the arm cannot effectuate a desired position, i.e. operating position, which is necessary when eating, dressing, washing, etc., of the hand. In order to compensate for the muscular loss the patients develop pathophysiological compensatory movements. The tetraplegics (C5) always need one arm to stabilise their sitting position in the wheelchair. The following provision has been made: the patient is provided with a myoelectric orthosis on the dominant hand only. Because of the reasons already mentioned, in all cases only one hand
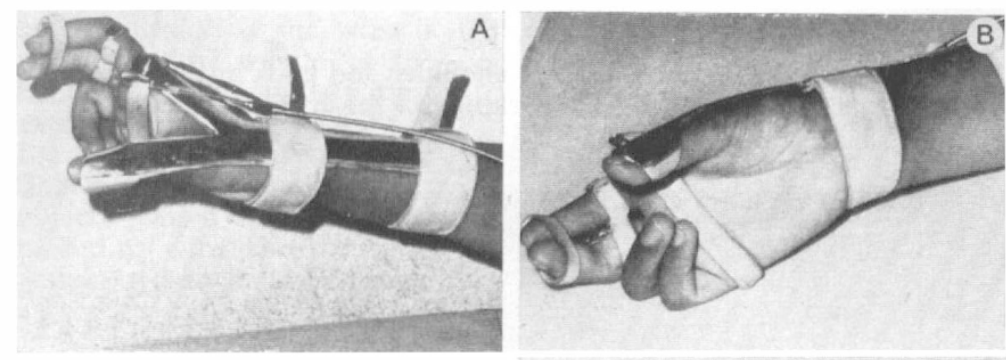

FIG. 5

A, The thumb is fixed in a slightly opposed position with a non-mobile splint. B, From the palmar view. In both figures the firstthree fingers are opened for pinch. C, Closed.

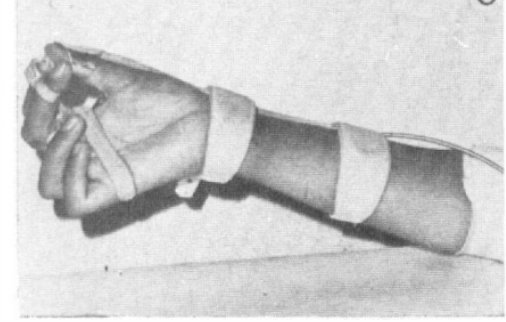

is used for prehension. Owing to loss of triceps function this group of patients propel the wheelchair by active flexion of the elbow. In order to sit safely in the wheelchair they move one shoulder and the elbow behind the wheelchair (fig. 7). The orthosis does not impede the movements in the wheelchair. So far nine patients have been equipped with a myoelectric orthosis.

Tertiary Patterns of Prehension. Patients with a fracture of C6 and complete loss of functions below, cannot move a finger and, owing to the loss of active elbow extension cannot lift themselves up in the wheelchair. At this level of injury (C6) the muscles of the shoulder, biceps, brachioradialis, extensor, carpi, radialis, longus and brevis remain active. The results are that they can be put into any wanted operating position; the forearm can be rotated and voluntary wrist extension is possible. Based on the remaining residual functions these injured persons develop substitute patterns of prehension of the arm and hand. In the Anglo-American literature they are known as trick movements. Analysis

$$
\text { I I } / 3-R
$$


of these trick movements indicates that all tetraplegics with complete loss of functions below C6 develop the same and typical trick movements. In contrast to the primary and secondary (1958) patterns of prehension the authors suggest naming them 'tertiary patterns of prehension'. The decisive characteristic is that

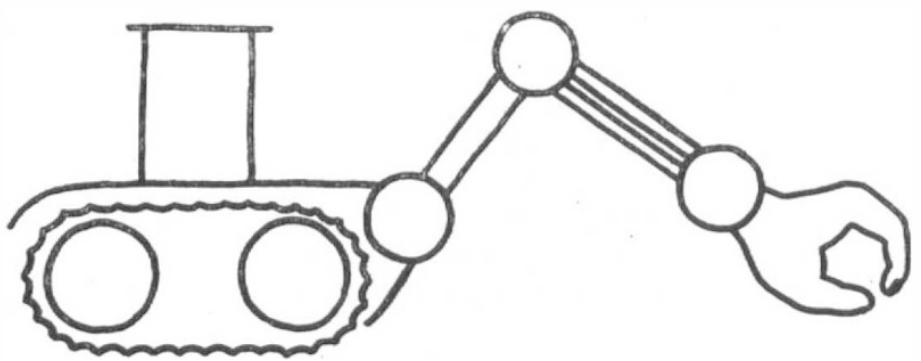

FIG. 6

The act of grasping starts in the shoulder and ends in the differentiated motions of the fingers, working like the arm of a caterpillar.

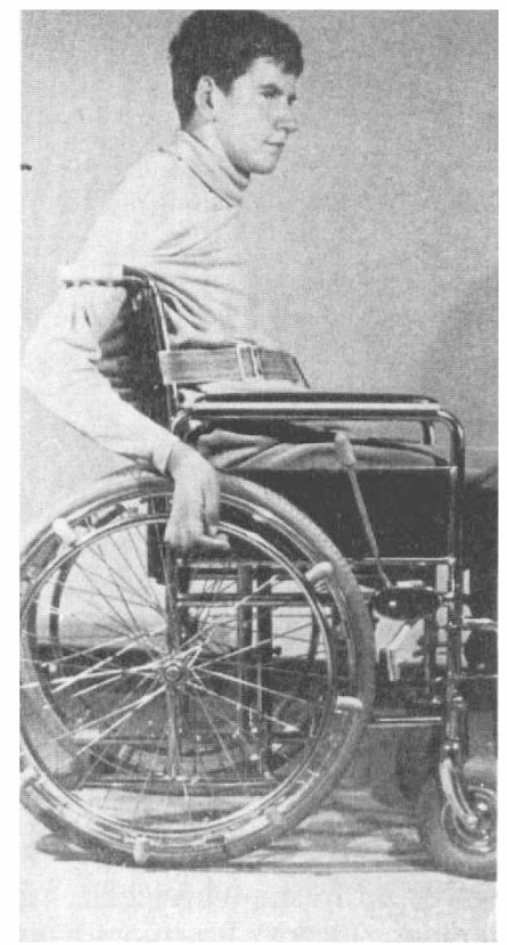

FIG. 7

A patient with a fracture of the fifth cervical vertebra and complete loss of functions. Owing to loss of triceps patients with a C5 level injury develop a special technique to propel the wheelchair! They put both arms behind the back of the wheelchair. By means of the weight of the forearms the elbows extend.

an object is not picked up by active flexion of the fingers but by a tenodesis effect, achieved by the remaining wrist extension. Small objects can only be picked, up with the tips of the first three fingers (like the pinch) and larger objects by closure of all fingers (like the grasp). These typical cervical patterns of prehension 
have been named 'tertiary pinch' (fig. 8) and 'tertiary grasp' respectively (fig. 9, A-C). Naturally, only small objects can be picked up with these kinds of prehension, depending on the power of the remaining voluntary wrist extension. The tenodesis effect is not sufficient for picking up and holding larger and heavier

FIG. 8

Tertiary pattern of prehension: 'passive pinch'.

FIG. 9

A, Complete flaccid paralysis of the fingers in a patient with a fracture of the fifth cervical vertabra. $\mathrm{B}$, With the wrist joint flexed the paralysed fingers are placed around the object-flexion at the wrist is caused by the weight of the hand. C, With voluntary wrist extension the flexor tendons of the fingers are shortened, the fingers are closed around the object, which now can be picked up when the forearm is supinated at the same time.

FIG. IO

Tertiary pattern of prehension, 'Patschhand-position'.
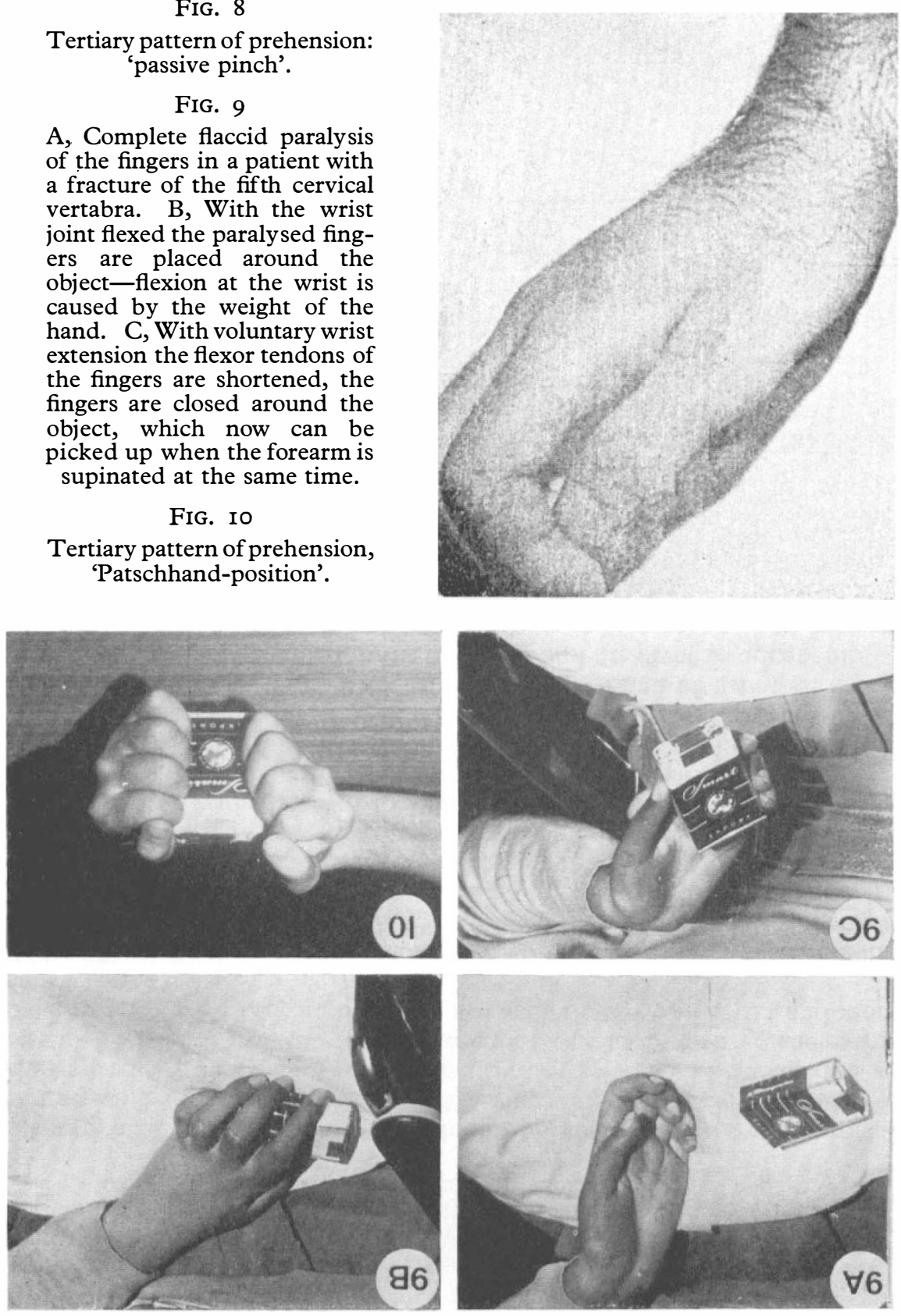
objects. These have to be taken up by simultaneous action of both hands. Since this form of prehension is similar to that of 'Patschhand' of babies, and because babies pick up things in the same way, we call this kind of tertiary pattern of prehension the 'Patschhand position' of tetraplegics (fig. Io). From experience it is known that in spite of persistent training the tertiary pinch cannot be formed gradated and the tertiary grasp cannot be formed powerfully. Therefore the rehabilitation of these patients (C6) has two aims:

I. That the pinch should be gradated;

2. That the grasp should be performed powerfully.

When these aims are achieved the patients will be able to perform all functions necessary in daily life, simple manual operations unaided, and also be employed in ordinary workshops.

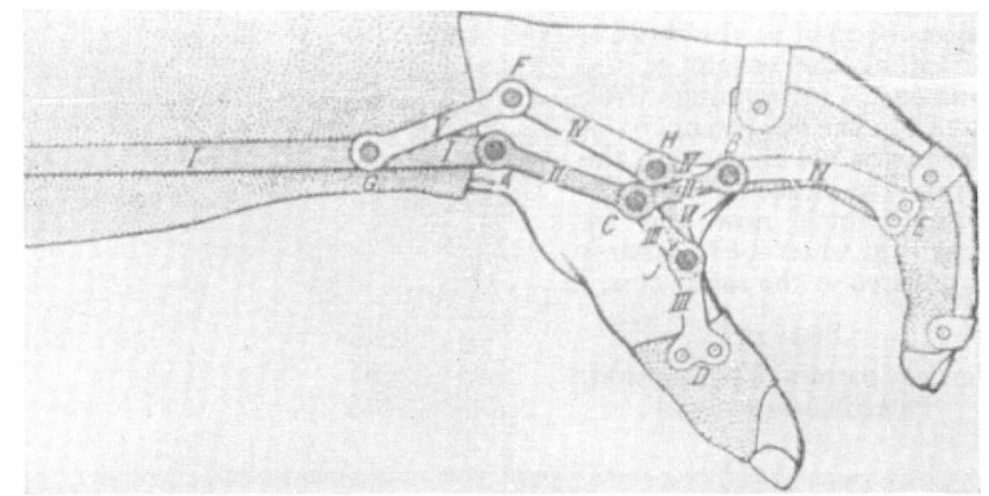

FIG. I I

The orthosis manufactured 1920 by Schmidt-Schrauder for a war disabled person, who had permanently lost all finger movements but had a remaining voluntary wrist extension.

Reciprocal Orthosis. In 1922 Schmidt published an orthosis manufactured by Schrauder (Schanz, I923) (fig. I I). A plastic reciprocal orthosis was developed in Houston (fig. I2) by Engen and Spencer (1964-68). These did not prove successful for several reasons, but the authors particularly disliked the extremely protruding lever. So they returned to the orthotic device of 1922 and modified it slightly (fig. I3, A.).

The orthosis of aluminium is made to measure. The thumb is fixed in a slightly opposed position with a non-mobile splint, index finger and middle finger are put in a mobile splint enabling them to be closed to a pinch with the tip of the thumb. Closure of the orthosis is attained by voluntary wrist extension in the course of which the MP joints of the index and middle fingers are flexed by a lever, i.e. in the orthosis the remaining wrist extension is used for flexion of two fingers by means of mechanical directing of the otherwise flaccid paralysed fingers. The stronger the wrist extension the more vigorous is the pinch achieved through the aid of the orthosis. Because of this, the training of extensor carpi radialis longus and brevis is very important. During the passive flexion of the wrist the index and middle fingers are extended in the MP joint and the orthosis opens (fig. I3, B). 


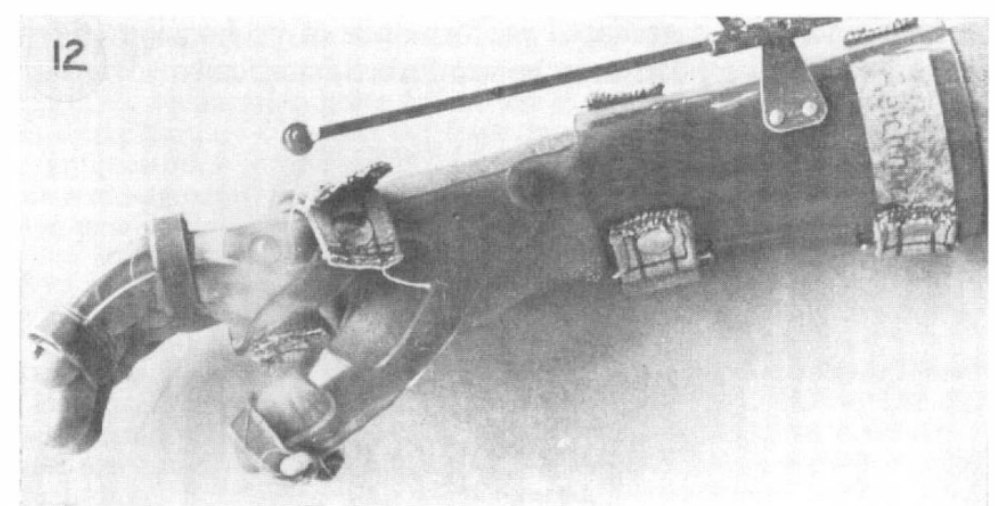

FIG. I2

The orthosis made out of plastic, developed by Engen and Spencer (1964-68) with the protruding lever.

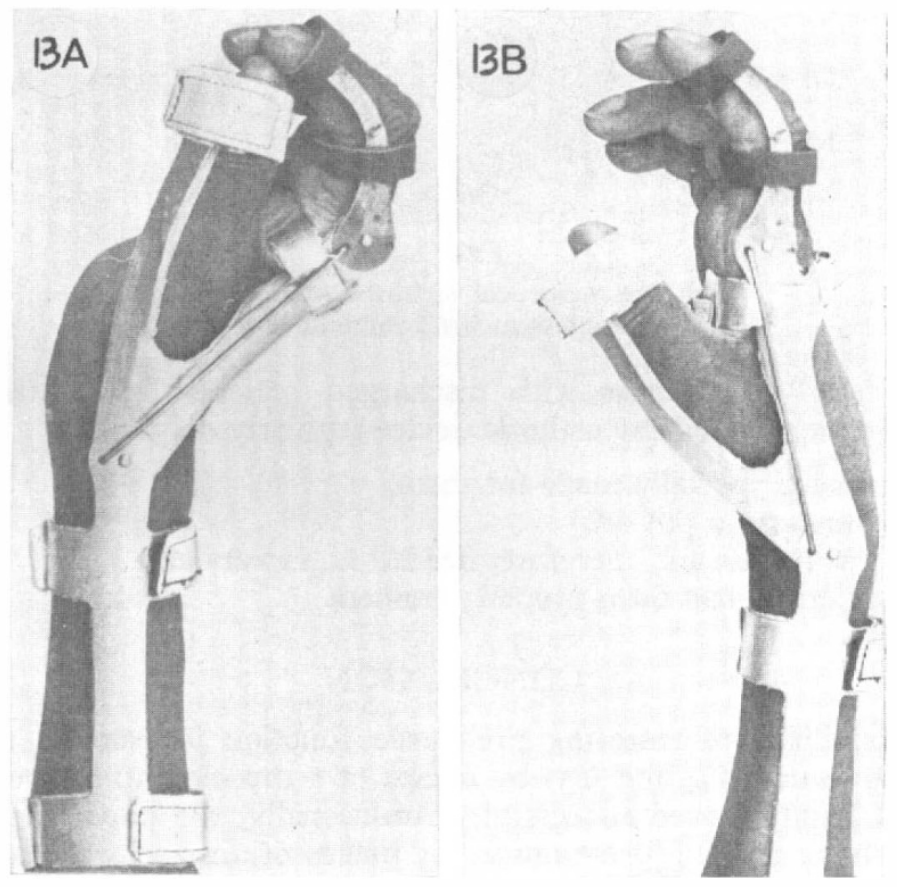

FIG. 13

A, Reciproval orthosis made out of aluminium. By voluntary extension of the wrist a gradated pinch with sensibility is achieved. B, During the passive flexion of the wrist the index and middle fingers are extended in the MP joint and the orthosis opens. 
Our patients with a fracture of sixth cervical vertebra and complete loss of functions get a reciprocal orthosis for the more skilful and stronger hand, so getting a strong pinch and a gradated performance of prehension (fig. I4). The power-prehension, however, can thus be reinforced, surgically.

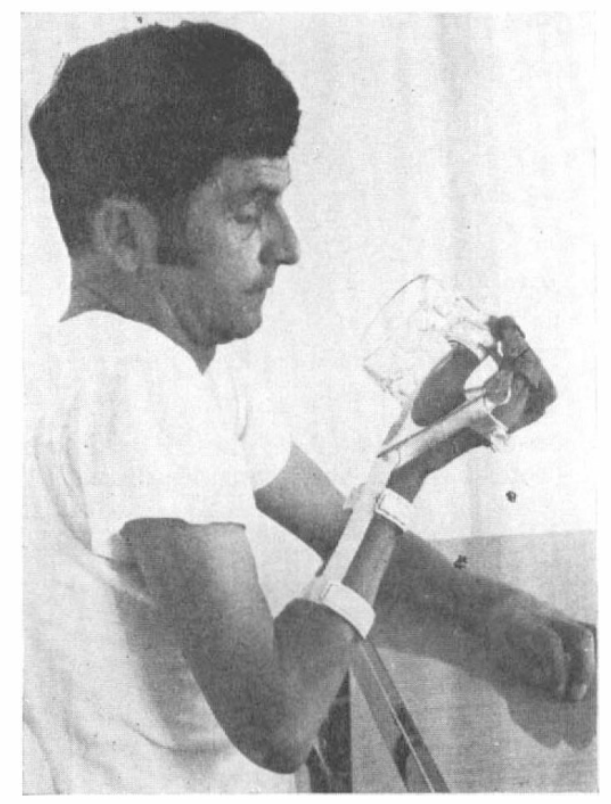

Fig. I4

With the reciprocal orthosis a patient can hold a glass in his dominant hand.

The authors' experiences with discharged patients led to the following results: most patients used the orthotic device regularly only if

(a) it had been specially made for them,

(b) if it was easy to put on,

(c) if it was robust and therefore, needed no repairs and

(d) if the patient had been properly trained.

\section{CONCLUSION}

The possibilities of restoring prehensile function in patients with a high cervical spinal injury $\left(\mathrm{C}_{4}\right.$ and $\left.\mathrm{C}_{5}\right)$ by means of a myoelectric control system on the dominant hand, proved successful. Additionally, the paper deals with our developed orthotic training programme (by means of a myoelectric hand) for the use of this device. Patients with a fracture of the sixth cervical vertebra and complete loss of functions developed patterns of prehension typical for this level of injury. It has been suggested that they are named 'tertiary patterns of prehension'. The tertiary pinch which cannot be performed powerfully, can be increased in the dominant hand by a reciprocal orthosis and the passive power prehension can be reinforced surgically. 


\section{RÉSUMÉ}

L'orthèse myoélectrique du coté dominant a été utilisée avec succès pour restaurer la fonction de préhension chez les tétraplégiques traumatiques hauts $\left(\mathrm{C}_{4}-\mathrm{C}_{5}\right)$. Le programme intensif de réeducation grâce à l'orthèse myoélectrique est aussi rapporté dans cet article. Des tétraplégiques complets par fracture de C6 ont développé des mouvements de préhension typiques pour ce niveau lésionnel. Le manque de force au niveau de la pince tertiaire peut être augmenté dans la main dominante par une orthèse réciproque et la force de préhension passive peut être renforcée chirurgicalement.

\section{ZUSAMMENFASSUNG}

Die orthopädisch-technischen Möglichkeiten zur Wiederherstellung einer Greifform bei hohen Halsmarkgeschädigten $\left(\mathrm{C}_{4}, \mathrm{C}_{5}\right)$ werden aufgezeigt. Dazu hat sich uns eine myoelektrisch gesteuerte Orthese an der primären Gebrauchshand bewährt. Außerdem wird eine von uns entwickelte Trainings-methode (mit Hilfe einer myoelektrischen Hand) zum Gebrauch dieses Behelfes berichtet. Nach kompletter Läsion bei C6 entwickeln diese Verletzten typische Greifformen. Ich habe vorgeschlagen, diese als 'tertiäre Greifformen' zu bezeichnen. Da aber der tertiäre Spitzgriff nicht dosiert und der tertiäre Grobgriff nicht ktaftvoll gebildet werden kann, verstärken wir die Kraft des Feingriffes an der geschickteren kräftigeren Hand durch eine reziproke Orthese und erhöhen die grobe Kraft des Faustschlusses durch eine handchirurgische Operation.

\section{REFERENCES}

Engen, T. J. \& Spencer, W. A. (1964-68). Final Report of Project RD-I564, Houston, Texas.

LoNG, CH., II. (1970). Ampersand Report SRS Grant No. RD-2377-M.

Schanz, W. (1923). Handbuch der orthop. Technik. Stuttgart: Fischer.

ScHuY, S. \& TöPKER, H. (1973). Elektrotechnik und Maschinenbau, Heft 4, Jahrgang 90.

Stauffer, E. S. \& Nickel, V. L. (1973). Int. F. Paraplegia, I0, 3-IO.

StÖGER, M. \& LEDERER, G. (I97I). Z. Orthop. 109, 239-243.

ZRUBECKY, G. (1958). Z. Orthop. 89, 54I-547.

ZRUBECKY, G. (I97I). Z. Orthop. und ihre Grenzgeb. 109, 239-243. 